ZS Research Square

\title{
A qualitative assessment of routine Vitamin A supplementation integrated with complementary feeding and family planning counselling within a six-monthly contact point program
}

Diana Ofori Owusu ( $\nabla$ oforiowusud@yahoo.com )

Dalan Development Consultants

Daniel Kamara

Dalan Development Consultants

Fatu Yumkella

Dalan Development Consultants

Mary Hamer Hodges

Helen Keller International

\section{Research Article}

Keywords: Integrated, vitamin A supplementation, complementary feeding, family planning

Posted Date: February 7th, 2022

DOl: https://doi.org/10.21203/rs.3.rs-1308405/v1

License: (c) (i) This work is licensed under a Creative Commons Attribution 4.0 International License. Read Full License 


\section{Abstract}

\section{Objectives}

To assess the relevance, effectiveness, efficiency, impact, sustainability, learning and replicability of the transition from mass vitamin A supplementation to a routine six monthly contact point, integrated with complementary feeding and family planning counselling.

\section{Study design}

Program performance was assessed taking into consideration the knowledge, attitudes and practices of both healthcare providers and caregivers to understand barriers and enablers to service uptake. A cross sectional qualitative survey with 63 key informant interviews with stakeholders and implementation staff and focus group discussions with 60 caregivers. Data was transcribed then coded through a framework analysis (developing themes from specific objectives) and thematic analysis (developing emerging themes not identified by the objectives).

\section{Methods}

The 'routine six-monthly contact point' included vitamin A, Albendazole, growth monitoring plus the promotion of optimal infant and young child feeding practices with complementary feeding demonstrations, the promotion of personal and food hygiene, access to confidential, family planning counselling and the provision of modern contraceptives for caregivers including hormonal implants.

\section{Results}

The six-monthly contact point was found to be highly relevant, effective, efficient, with a positive impact on maternal and child health and sustainable. Lessons for replicability focus mainly on the extensive need for sensitisation of men/husbands and religious leaders regarding family planning. The challenges that prevent health seeking behaviour included distance to the facilities, poor roads, difficulty/cost of transportation and workload. The participatory complementary feeding demonstrations and community health workers encouraged attendance and appear to have contributed to the reduction of malnutrition but stockouts of essential commodities remain discouraging.

\section{Conclusions}

The program has been fully adopted by all levels of the health sector. The integration of family planning and its acceptance by caregivers is commendable and there has been an increase in the uptake of modern especially hormonal implants. This integrated approach was thought to have contributed to the reduction of childhood malnutrition. Recommendations include increasing awareness of affordable, accessible local foods for complementary feeding, more training for health workers on reporting and family planning counselling for the provision of long-term reversible contraceptives and further sensitisation of men and religious leaders on the importance of child spacing.

\section{Background}


The goal of maternal and child health interventions in Sierra Leone is to accelerate the reduction in morbidity and mortality and ensure wellbeing ${ }^{1}{ }^{2}$. The maternal mortality rate is high despite an almost $40 \%$ reduction to 717 per 100,000 live births in $2019^{3}$. Similarly, child mortality is amongst the highest in the world although it has reduced by more than half to 109 per 1,000 live births in $2020^{4}$. Childhood malnutrition rates are also declining, and stunting has fallen from $40 \%$ in 2005 to $26 \%$ in 2021 whilst vitamin A deficiency was $18 \%$ in $2014^{5,6,7}$. Chronic malnutrition in children under two years of age may permanently damage their cognitive and physical development, limiting their potential and that of the country ${ }^{8}$. Child mortality rates in Vitamin A deficit populations can be reduced if Vitamin A supplementation (VAS) is given at six months and every six months until 59 months of age ${ }^{9}$. Malnutrition can be further reduced if optimal feeding practices are observed (exclusive breast feeding from birth to six months of age when nutrient-dense complementary foods should be introduced, with continued breast feeding to 24 months). Adverse child health (stunting and deaths) can be significantly reduced with childbirth spacing to 24 months $^{10}$. In 2012 the Government recognized the significance of unplanned teenage pregnancies and committed to reducing teenage pregnancies, increasing access to modern contraception and to improving commodity supply chain management ${ }^{11,12,13}$.

Helen Keller had supported mass VAS campaigns since 2004 and piloted the transition to routine VAS integrated with the promotion of complementary and family planning counselling in 2011. During Ebola (2014-2016) when caregivers were wary of contact with health workers, attendance at health facilities that were offering the 'integrated VAS package' was significantly higher than those that did not offer the complementary feeding and family planning counselling ${ }^{14}$.

By 2017 the Directorate of Food and Nutrition (DFN) and UNICEF recommended that this 'integrated VAS package' be used for the full transition from mass to routine VAS as the six-monthly contact point. The transition was phased in over four years to allow for the training of health workers on family planning counselling and the provision of hormonal implants and is now operational nationwide ${ }^{15,16,17}$. This evaluation was commissioned to understand the knowledge, attitudes, and practices of service providers, and the barriers and enablers to the sixmonthly contact point.

\section{Methodology}

The cross-sectional qualitative survey engaged stakeholders, implementation staff at each level of the health system using key informant interviews (KII) and focus group discussions (FGD) with beneficiaries. The data collection toolsets assessed the relevance, effectiveness, efficiency, impact, sustainability, learning and replicability in Kenema, Pujehun and Port Loko districts representing three phases of transition.

\section{Tools and study design}

Topic guides were developed, pretested and revised (Supplementary material 1-5). Overall, a total of $63 \mathrm{KIIs}$ were conducted by convenience sampling comprising national (10), district (20), chiefdom (27) and community levels (6). At national level there were representatives from Irish Aid, the DFN, the Reproductive Health and Family Planning Program (RHFPP), UNICEF, and religious leaders (both Christian and Muslim) from a national NGO (FOCUS 1000) that supported advocacy related to family planning. District interviews included the District Medical Officer/Health Sister, Nutritionist, Community Health Workers (CHW) Coordinator, Social Mobilization, Operation 
and/or the Monitoring and Evaluation Officers (depending on their availability). At chiefdom level two CHWs in each of three chiefdoms per district (18) and one health worker at a Peripheral Health Unit (PHU) from three chiefdoms[1] (9) were interviewed. At community level two men (spouses of caregivers) in each district (6) were interviewed. Overall, a total of 60 caregivers of children 6-59 months old participated in the FGDs (20 per district).

\section{Data analysis}

Data was transcribed then coded through a framework (developing themes from specific objectives) and thematic analysis (developing emerging themes not identified by the objectives). The Organization for Economic Cooperation and Development/Development Assistance Committee criteria formed the basis for the assessment in relation to the target beneficiaries and the MoHS strategic plan.

\section{Fieldwork}

The two local consultants conducted the national level KII. Three teams of two fieldworkers conducted the district, chiefdom and community level KII and FGDs over a period of eight days in July 2021.

\section{Results}

\section{Relevance}

The integrated six-monthly contact point aligns with government developmental goals:

"It is being implemented at government facilities by government staff and the monitoring and supervision is also done by the government officials to ensure sustainability." National

The six-monthly contact point enables integrated service delivery:

"We start with the health education, followed by growth monitoring, and the children that are for immunization. Then we check the health status of the mothers, because you cannot expect a sick mother to take care of a child." $\mathrm{PHU}$

Health workers undertake outreach services to remote areas;

" we go monthly to access people that were not able to make it at the clinic on Fridays and the places are closer to them so they will just come and get the service that they missed." PHU

Caregivers noted that the visit affords the health worker time to examine children unlike the campaigns.

"It is better when you come to the hospital because if anything is wrong with the child, they can give treatment." $\mathrm{PHU}$

\section{Efficiency}

Transition from an already established system required strong, inter-sectoral approaches. 
"The collaboration of government with the international NGOs and partners made it easier to transition from the campaigns to the six-monthly contact point." National

Activities were planned with the DHMTs who assigned duties to ensure efficient use of resources:

“ existing resources that are available can be tapped and they were also trained on how to use the monitoring and reporting tools that are part of the DHIS." National

Mass training were conducted for all PHU 'in-charges' on the implementation and reporting:

"Helen Keller trained nurses from all government facilities on how to administer vitamin A and Albendazole and how to teach caregivers on hygiene practices, the preparation of the complementary feeding and family planning." National

$\mathrm{PHU}$ 'in-charges' cascaded the training to junior colleagues:

"We were taught that as soon as lactating mothers completes the six months exclusive breastfeeding, their babies should start taking vitamin A and continue every six months till five years. They told us that after a child is six months, they will introduce complementary feeding. As soon as mothers give birth, we should start talking to them about family planning and show them all the particulars so that she will know about child spacing. She may decide to accept if she is not using LAM after 40 days to start taking family planning to space her children." PHU

Social mobilizer officers held meetings with chiefs, market women, district councillors, chairpersons of the interreligious council, drivers' union and motorbike riders union representatives:

"We create demand for health services so that people would go on their own even if they have to walk long distance to the PHU." District

PHUs in-charges attend monthly district meetings organised by the M\&E Officer:

"Where the DHMT, nutrition units and EPI discuss observations made during monitoring at the health facilities." National

Supportive supervision was performed by using an agreed checklist and the results sent electronically were widely shared with the National Nutrition Coordination Committee:

"Looking at VAS, deworming, complementary feeding, growth monitoring and promotion- that has to do with surveillance, and then all of the interventions like family planning, HIV and Aids, immunization all of this coming together was good for program integration" National

The RHFPP monitored family planning counselling and provision:

"Whenever we identify gaps, first and foremost we engage the DHMT members that are in-charge of these facilities and their service providers. We sit down with them and tell them about the gaps, and we plan a way forward. We do follow up to ensure that has been addressed." National

Data collection from PHUs and is sent via the DHMT to the DFN and analysed with UNICEF support: 
"At the end of the day's work, the nurses will take a photo of the record they have and send it via WhatsApp and sometimes through email." District

District nutritionist and M\&E officers conduct quality checks on the monthly summaries:

"When I look at the in-charges reporting, I sometimes see inconsistencies on nutritional data, so I work together with the focal person to correct the discrepancies." District

\section{Effectiveness}

Caregivers appreciated the six-monthly Albendazole given to children from 12 to 59 months to reduce the burden of intestinal worms plus the vitamin A and immunisations:

“ some years back, it was very common for babies that had just been weaned to be infested by worms. It used to affect newly weaned children because they would start eating all kinds of foods but because of the Albendazole they are giving us it is no longer common." FGD.

“....we are blessed to have access to vitamin A and other vaccines which have prevented our children from many childhood diseases. Now we don't have blindness, polio, and measles, thank God for the clinic" FGD

Immunization is done weekly in most of health facilities and daily in a few instances:

"Our own immunization is done daily; we have a lot of vaccines in our fridge. If the child is due for vaccination, we offer the service. We are here every day, even on Sundays." PHU

Caregivers appreciated that routine visits to health facilities had resulted in healthier children:

"Coming to the clinic has improved the health of my child, because she used to be very sickly, but due to the health education on the feeding, everything is now fine." FGD

Mothers are counselled on nutrition and how to prepare, provide and store local foods in a hygienic manner. Benni is recommended as a source of protein and essential fats and all mixtures containing benni are referred to as 'local/homemade' bennimix18. There are many varieties produced in different communities and seasons dependent upon the availability of other ingredients 19.

“Every PHU has its nutritional corner with counselling cards, our people in the village learn by seeing. The nurse will demonstrate to them the various types of food, how to prepare them and show the food tray and counselling card." District

One participatory approach to complementary food demonstrations used a pre-roasted blend of benni, sorghum and beans that only required caregivers to add hot water to make a porridge which they then feed their infant before returning home. This approach also introduced personal hygiene, using a cup and spoon (not hand) to feed the child and not to force feed a sick child.

"And every procedure in preparing food one has to wash her hands, so I learnt a lot. We learnt you cannot encourage flies to sit on baby's food, some people knew this before whilst others didn't know. I now know that when I am ready to feed my child, I should not use dirty water to wash my hands, but clean water and soap." FGD 
In addition, there are radio broadcasts and posters recommending the available, affordable local foods

"We have posters demonstrating the importance of food like potato leaves, palm oil and we also ensure to provide such information in our radio discussions" District

Other health facilities encouraged caregivers to bring local food for demonstration:

"We sometimes ask caregivers to come with other food stuffs like beans, benni, groundnut, oil as the case may be so that we will demonstrate how to go about the process by directing them so that when they go home, they will be able to do what they have been told to do. Complementary demonstration is done monthly which is the cooking but for the other demonstrations, we do it weekly. If we prepare benni this week, the following week we will prepare rice mixed with palm oil, beans, potato leaves, fish and also pumpkin." PHU

Caregivers explained how to prepare complementary food using different ingredients:

“We use bonga fish , jumbo magi , rice, benni, beans and groundnut; put all in a pot, roast it and pound it into powder, and then you have your bennimix formula locally. When you need it, you only have to boil it as porridge or sometimes some people stir it." FGD

Food demonstrations were also changing foods taboos:

"We still have people with the old traditional beliefs that you should not give an egg to a child to eat and if the mother cooks, the meat should not be given to the kids." District

Health workers are keen to see that caregivers follow the guidelines:

." ...You might have taught them but they will forget later so if they come back and I see any complication on the child, from there I will begin to sensitize her again." PHU

Caregivers explained how they were advised during the demonstrations:

"The food demonstrations have been very helpful for me because before now, we never saw anything wrong in feeding our babies with solid foods but we have learnt a lot." FGD

Health workers and caregivers believed the food demonstrations had helped reduce malnutrition:

"The demonstrations help prevent malnutrition because they are receiving the right nutrient, at the right age, the right time and the right texture of the food and hygiene protocol." PHU

"Before the introduction of this complementary feeding in the clinic, malnutrition was rampant especially in the rainy season, but now there is no case in this community, because we know the foods to give our children when they are six months and we know how to prepare it." FGD

The food demonstrations have economic benefits:

"On the side of the family, it is very economical. Because before now they didn't know that some of this local food that they have in their backyard garden are so important for the kids; instead, they were using expensive food that some could not afford." PHU 
Caregivers are aware that the local/home-made bennimix is cheaper than imported food:

"The bennimix is beneficial because it reduces the cost of buying baby food and it is obvious that we don't earn much so for me it is a good idea and I am very grateful." FGD

Health workers promote the introduction of complementary feeding when infants reach six months:

" If the child is six months, I will ask the mother to change the diet and if not, I will tell them to be patient a bit." $\mathrm{PHU}$

Family planning counselling services to reduce maternal mortality and improve families' quality of life:

“People are giving birth to too many children and some are so poor and uneducated to the extent that they don't know the effect that will have on their livelihood. So, we were trained to ensure that people have children by choice. That is the only way we can get rid of poverty out of the communities and in the country as a whole. If you have a child today in less than one year or one year six months you have another child, the children will not grow well because you do not have the required food for them. But with family planning, you will be able to space your family so that the wife and the husband will be at peace." PHU

Health workers had set up private rooms for family planning counselling or use the in-charge's office:

"It's a consultation room for just two people; the client and I, except if there is need for the patient's relative or caregiver to be present there. We highly respect the privacy of our patients especially a community like this that frowns at family planning..." PHU

Caregivers attest to the privacy involved in family planning services provided at facilities:

" because some do talk a lot that's why the nurse doesn't allow the two of you together in. If you say, 'I come to accompany her' they will tell you to wait for her outside." FGD

There are health facilities with "the adolescent friendly corner" where they cater for teenage girls;

"Before this intervention, women and girls in this community were giving birth to children as if they were in a competition." PHU

Clients are not coerced but are counselled to understand the importance of child spacing:

Our responsibility is to ensure that the person understands the various services and you will have to give her the free will to decide." PHU

"They display the various commodities that they have after talking to us about prevention; that they have the depo, coil, captain band [hormonal implants] and pills. They tell us the wide range of choices of family planning commodities which are all free of cost." FGD

"I thought family planning was only practiced by educated women or office workers." FGD

Caregivers realize the dangers of having too many children especially without spacing pregnancies: 
"We are farmers, if for instance I have one child around three years who cannot walk properly and the other around one year and I am also pregnant. In the morning my husband will go ahead to the farm, I have the two kids to carry to the farm and I am pregnant, I will force the 3-year-old to walk faster and carry the year old on my back.

Remember I am weak and hungry carrying all these children with pregnancy, I will suffer more than the man. I see it necessary to talk to the husbands to allow us to join the family planning, so that we'll space the kids, and the suffering will be less." FGD

Birth spacing has improved family finances:

"Well, using contraceptives has helped me and my family to plan our family well in a way that we are able to take care of all our financial problems." FGD

" if there was no family planning some homes must have been devastated because women will just be giving birth." FGD

\section{Impact}

During the transition community engagement structures were either developed, revitalized or modified:

"The role of the CHWs and the Mother Support Group has helped increase awareness on maternal, infant and young child feeding that has an impact on the reduction of morbidity and mortality. They have supported getting children vaccinated and mothers to plan their families in order to space childbirth and see how to care for those that they already have." National

The complementary feeding demonstrations appear to have helped reduce malnutrition:

"There was a mother who was feeding her six-month-old baby with biscuit and ORS, the child's health deteriorated until she came here, and we taught her how to prepare this bennimix; now the child has recovered. There are lots of that kind of story." PHU

"The benefits that we are getting is that their children are getting healthier, and the caregivers are constantly getting information on health-related issues such as the importance of vitamin A for prevention of blindness and albendazole which has reduced worm infestation." District

"Another important success is that infant mortality rate has also reduced because of the complementary feeding and the vaccine that has been given to the children." $\mathrm{CHW}$

Lessons learned and replicability

\section{Enablers}

Coordination with CHWs and the mothers support groups;

" especially for older children because that is where we were having low coverage." National 
" health workers were able to better coordinate because they were more aware the needs and problems of these communities and the communities themselves accepted it and they used this cordial relationship to pass on health-related messages." District

Coordination with traditional leaders:

"The Paramount Chief called a meeting the last time and talked to us about family planning. He said that people should not be just giving birth rapidly...." FGD

\section{Barriers}

One-day's training was insufficient:

“... you cannot do in-charges training in a day if you have 50 persons in a classroom." National

"If you don't know about basic nutrition, you will misinform the client." PHU

Not everyone is pleased with the transition:

" some of us are coming from very far communities and sometimes, we find it very difficult to get here because we have to make sure we do our domestic work in the morning." FGD

Some caregivers are preoccupied with income generation:

" it is better if the nurses go to the community. Even if they don't meet the parent, they'll ask for the age of the child around or in the compound and drop the vitamin A." FGD

Difficulty and costs of transportation:

"When the water level goes up, they will never cross over here until we go and meet them. Those on the land, the cost of motor bikes sometimes affects them, because some can't afford it." PHU

No resources for $\mathrm{CHWs:}$

"If CHWs in the past have been empowered to treat diarrhoea because they were able to actually carry ORS..., then Vitamin A should have been integrated..... So, I think we missed an opportunity." National

Supply chain weaknesses remain:

"If you see our monthly chart for Vitamin A and Albendazole you will notice that we have zero for some months. The supplies come but they are not enough" PHU

Stockouts discourage attendance:

"When there are stock outs and caregivers are not getting the service, they want it is difficult to return; especially those whose husbands are suspicious of their movements." PHU

" we do not have the IUCDs and implants. Most patients come for these services, but they are not available, and we cannot ask them to buy them because family planning services are free and if you ask the patient to come at 
another time the next time, she will be already pregnant." District

"For the implants, we have stock out of local anaesthesia, Povidol, and gauze and these problems are not just for this facility but for the whole district." PHU

Some caregivers cannot afford or access even the local ingredients:

"They give them rice pap because that is what they can afford.' $\mathrm{CHW}$

"They do not have the chance to buy it all the time in this community as they have to go to the periodic market in other towns in search of those ingredients like beans and others." CHW

The DFN developed and disseminated a complementary feeding recipe book and Food Based Dietary Guidelines, but these are not widely used20,21.

“ [caregivers] don't understand that some of the local food that they produce can also serve as complementary food, instead they may decide to buy tin food." National

"In most cases caregivers are not aware of the usefulness of their own local foods in providing the nutrients to support their child growth but resort to manufactured foods which are sometimes above their means." National

" demonstrations should be context specific. The food that is available in one district may not be readily available in another." National

" they told us to be giving the child other nutritious foods like eggs, corn, potatoes, yams, fish and a lot more." FGD

Some men do not agree with their wives using family planning. If women insist it can lead to fights or even divorce. Most women who join family planning do so without informing their husbands.

“ I joined secretly. When he asked me why I wasn't getting pregnant, I told him God's time has not reached yet. When it is time, I will get pregnant" FGD

Men constitute a barrier to family planning:

"The sooner they detect it [Jadelle] they will straight away come to the health facility to get it removed; the only alternative now is the injection. With the injectable you take it quietly and leave the card with me, when your time is due you come, or I remind you to come." PHU

Some men believe their wives use family planning to engage in extramarital affairs:

" no sooner your husband learnt that you have started taking family planning, those things that you were doing that were not considered serious, they would start taking them very seriously. Whatever you do now, he would begin to ask plenty questions." FGD

Only one spouse admitted that his wife was on family planning and his change of mind happened only when she started visiting the PHU even though he had been aware:

" now I thank God as we do not expect unwanted pregnancy." Spouse

Page $11 / 16$ 
One spouse admitted that his wife had pleaded to be allowed to join family planning, but he had refused:

"Yes, we have discussed family planning. She told me that she wanted to rest a little on childbearing because she is too young to have the number of children she is presently having. I agreed, but I told her it shouldn't be for five years or more because childbearing is in the hands of God. There are people who are looking for children, but they don't have them so if God has given them to us, then we shouldn't deny them. The only thing is that we should pray so that God will make provision for us so that we will be able to take care of them." Spouse

Religion also limits family planning uptake:

"Sensitization in family planning should continue because we are still having challenges, especially with the religious people because there are some verses in the Quran that says you should not kill your child and so for some people when they read that verse, they will think that the purpose of family planning is to kill their babies. The same thing also with Christians, so we need people to explain that killing a child and preventing pregnancy are different." National

Some religious leaders assert that the Bible and Quran, have passages that are against family planning:

"It's very fearful and haram/forbidden" FGD

"Modern contraceptives are the root cause of all manner of diseases today, and that it is not good for anything. He [Imam] further said that in their days their mothers used to give chance to nature to play part, that is women may deliver children up to the time of God's will. But today if you want a woman to give birth you have to beg her, because it's no more God, but they control the birth, which is very sinful and must be accounted for on the day of judgement for killing human being." FGD

Few health workers have the expertise to insert hormonal implants:

"I am the only person trained to insert implant, which means if I am away for a workshop or any other activity that area will remain vacant. With that one-day absence so many things could go wrong, but if the two are trained my colleague will render the service." PHU

In most communities family planning services are free but not always:

"Money is the major barrier in getting family planning in this community. You have to pay for all family planning services, that is one of the main barriers." PHU

Women reported that they paid Le25,000 for a hormonal implant insertion and again for removal. Injectables and pills cost between Le10,000 and Le15,000.

\section{Sustainability}

The program has been integrated into PHU weekly schedules and annual DHMT workplans and budgets. Caregivers spoke of the camaraderie between them and service providers that encourages health-seeking behaviour. In 2021 the CHWs curriculum and entry criteria were revised and now they report directly to the local PHU-in-charge who delegates, monitors and supervises their performance rather than reporting directly to the DHMT22,23.

Page 12/16 
Helen Keller worked with the religious leaders in FOCUS 1000 at national level to fully understand family planning and modern contraception and identify passages in the Bible and Quran that would support birth-spacing24. They then worked together with the DHMTs to advocate with religious leaders in the districts and cascaded those advocacy meetings to every chiefdom so that religious leaders would inform the men in their congregations. This chiefdom-level advocacy with district and village level religious leaders was repeated in the second year of transition and contributed to the high level of awareness of family planning despite ongoing hesitancy.

Men are the heads of households and the decision makers. Their opposition to family planning is a challenge for their wives who understand and desire spacing of childbirth.

"It is important to educate men on family planning because as women some of us find it very difficult to do some of these things without the support of our husbands." PHU

Caregivers believed that if health workers spoke directly to their husbands, it would be Dmore effective:

"The worst of it some of the men will not agree for us to take the family planning but if they also know about the importance of taking family planning it will be very good for all of us." FGD

Religious leaders command the most respect in their communities:

"The message is as important as the messenger" National

" if they involve the Imams and the Pastors, I can say we have gone halfway in our sensitization. Because they have larger following that listens to them more than anyone else." PHU

\section{Conclusion}

The program has been fully adopted by all levels of the health sector. The integration of family planning and its acceptance by caregivers is commendable and there has been an increase in the uptake of modern contraception. This integrated approach was thought to have contributed to the reduction of childhood malnutrition.

Recommendations include increasing awareness of affordable, accessible local foods for complementary feeding, more training for health workers on reporting and family planning counselling for the provision of long-term reversible contraceptives and further sensitisation of men and religious leaders on the importance of child spacing.

\section{Declarations}

\section{Authors contributions:}

DOO and DK performed the national interviews, transcribed and coded all KIls and FDGs then did the analysis and drafted the report. MH provided technical background, reviewed and revised the manuscript. All authors have seen and approved the final manuscript.

\section{Ethics approval and consent to participate}


The protocol was approved by the Sierra Leone Ethics and Scientific Review Committee. s were guaranteed anonymity and confidentiality. The teams introduced the purpose of the assessment and emphasized the use of the analysis to strengthen health service delivery. Participants were not remunerated in keeping with standard ethical practice for voluntary participation. Confidentiality, protection of participants, integrity, and accuracy

\section{Consent for publication}

All authors have consented to this publication

\section{Availability of data and materials}

Available upon request

\section{Competing interests}

There are not competing interest

\section{Funding}

This evaluation was funded by Irish Aid-Sierra Leone. The transition from mass VAS campaigns to the integrated six-monthly contact point was funded by Irish Aid-Sierra Leone and Government of Canada through UNICEF.

\section{Acknowledgements}

The authors wish to thank Umu H. Jalloh, Helen Keller for her support in study design, interviews guidelines and initial review of the report. We thank all participants for their time, attention and patience during this process. We would like to finally thank all members of the Helen Keller team, the DHMTs and PU staff who have worked hard to make this transition to routine VAS a success.

\section{References}

1. Sierra Leone Reproductive Maternal Newborn Child and Adolescent Health Strategy 2017-2021 https://www.afro.who.int/publications/sierra-leone-national-reproductive-maternal-newborn-child-andadolescent-health-policy

2. Ruel MT, Alderman $\mathrm{H}$, and the Maternal and Child Nutrition Study Group Nutrition-sensitive interventions and programmes: how can they help to accelerate progress in improving maternal and child nutrition? Lancet June 6, 2013http://dx.doi.org/10.1016/S0140-6736(13)60843-0

3. Ministry of Health and Sanitation, Sierra Leone Demographic and Health Survey, 2019. https://www.statistics.sl/images/StatisticsSL/Documents/DHS2018/sldhs2019kir.pdf

4. UNICEF State of the Worlds' Children 2020. https://www.unicef.org/reports/state-worlds-children-2021 
5. Statistics Sierra Leone, Multiple Indicator Cluster Survey, 2005,

https://www.unicef.org/sierraleone/media/391/file/SLMICS-Report-2017.pdf.pdf

6. Ministry of Health and Sanitation Sierra Leone National Nutrition Survey, 2021 (in press)

7. Ministry of Health and Sanitation Sierra Leone, UNICEF, Helen Keller International, and WHO. 2013 Sierra Leone Micronutrient Survey. Freetown, Sierra Leone; 2015. https://groundworkhealth.org/wpcontent/uploads/2016/03/SLMS-Report_FINAL_151203.pdf

8. Abdullahi LH,Rithaa GK,Muthomi B,Kyallo F,Ngina C,Hassan MA,Farah MA. Best practices and opportunities for integrating nutrition specific into nutrition sensitive interventions in fragile contexts: a systematic review. BMC Nutr.2021 Jul 29;7(1):46.doi: 10.1186/s40795-021-00443-1.

9. Imdad A, Mayo-Wilson E , Herzer K, Bhutta ZA. Vitamin A supplementation for preventing morbidity and mortality in children from six months to five years of age. Cochrane Database Syst Rev. 2017 Mar 11;3(3):CD008524. doi: 10.1002/14651858.CD008524.pub3.

10. Sanni Y, Olalekan AU, Michael E, Ghose B \& Vissého A. (2019) Effects of birth spacing on adverse childhood health outcomes: evidence from 34 countries in sub-Saharan Africa, The Journal of Maternal-Fetal \& Neonatal Medicine, DOI: 10.1080/14767058.2019.1576623

11. Government of Sierra Leone. National Strategy for the Reduction of Teenage Pregnancy (2013-2015) https://healtheducationresources.unesco.org/sites/default/files/resources/Sierra_Leone National_Strategy_for_the_Reduction_of_Teenage_Pregnancy.pdf

12. Government of Sierra Leone. National strategy for the reduction of adolescent pregnancy and child marriage (2018-2022) https://sierraleone.unfpa.org/sites/default/files/pub-

pdf/National\%20Strategy\%20for\%20the\%20reduction\%20of\%20Adolescent\%20Pregnancy_final_Oct\%202.pdf

13. Ministry of Health and Sanitation Sierra Leone Family Planning Costed Implementation Plan https://fp2030.org/sites/default/files/SL-CIP-Jan30_AL_JW.pdfhttps://fp2030.org/sierra-leone

14. Attendance for essential nutrition actions during the Ebola emergency demonstrate resilience when fully integrated maternal and child health services were available in Freetown, Sierra Leone, Micronutrient forum, Cancun Mexico, 2016

15. Koroma AS, Ghatahora, SK, Ellie M, et al. Integrating reproductive and child health services enables access to modern contraception in Sierra Leone Int J Health Plann Mgmt. 2019; 1-13. doi: 10.1002/hpm.2728

16. Koroma AS, Conteh SG, Bah M, Kamara HI, Turay M, Kandeh A, Macauley A, Allieu H, Kargbo AA, Sonnie M, Hodges $\mathrm{MH}$. Routine vitamin A supplementation and other high impact interventions in Sierra Leone. (2020) Matern Child Nutr;16:e13041 doi: 10.1111/mcn.13041

17. Koroma AS, Kamara HI, Moses F, Bah M, Turay M, Kandeh A, Kandeh S, Allieu H, Kargbo A, Macauley A, Hodges MH, Doledac D. (2021) The impact on key indicators of reproductive and child health after changes in program modalities in Sierra Leone. Health Sci Rep. 2021;4:e297. doi.org/10.1002/ hsr2.297

18. Kanu PJ, Kanu JB and Zhou H. Studies on the physicochemical composition of Bennimix: A Traditional Weaning Food. American Journal of Food Technology 2 (7): 652-661, 2007 ISSN 1557-4571

19. Kanu PJ, Hinaga E, Sandy EH, Kandeh JBA, Bahsoon JZ and Zhou H. Production and Evaluation of Breakfast Cereal-Based Porridge Mixed with Sesame and Pigeon Peas for Adults, Pakistan Journal of Nutrition 8 (9): 1335-1343, 2009 ISSN 1680-5194

20. Ministry of Health and Sanitation, Directorate of Food and Nutrition Complementary Food recipes, 2018 
21. Food-based dietary guidelines Sierra Leone https://www.fao.org/nutrition/education/food-dietaryguidelines/regions/countries/sierra-leone/en/

22. Bauck A, Jalloh UH, Kargbo A, Hodges MH and Doledec D. (2020) Gender considerations whilst transitioning mass Vitamin A supplementation into integrated reproductive and child health programming in Sierra Leone. Health Policy Plan, Jun 3;36(5):673-683. DOI: 10.1093/heapol/czab037

23. Ministry of Health and Sanitation, UNICEF, Revised CHW curriculum, 2021

24. Semi-Annual report to Irish Aid, Helen Keller INTL, January 2019 